\title{
Kajian Kelimpahan Mikroplastik di Biota Perairan
}

\author{
Saptian Wisnu Sandra dan Arlini Dyah Radityaningrum*
}

\author{
Jurusan Teknik Lingkungan, Fakultas Teknik Sipil dan Perencanaan, Institut Adhi Tama Surabaya
}

\begin{abstract}
ABSTRAK
Sampah plastik dapat terdegradasi menjadi mikroplastik (MP) dan nanoplastik (NP) melalui proses fisik, kimia, dan biologis. MP didefinisikan sebagai partikel plastik kecil berukuran $<5 \mathrm{~mm}$. MP saat ini telah ditemukan di tubuh biota perairan, baik perairan permukaan maupun perairan laut. Tujuan penelitian ini adalah mengkaji MP pada biota perairan. Metode yang digunakan dalam penelitian ini adalah studi literatur terhadap artikel publikasi 10 tahun terakhir. Kajian dilakukan terhadap kelimpahan, ukuran, bentuk, warna, dan komposisi MP pada biota perairan permukaan dan laut. Review dilakukan terhadap penelitian di Indonesia dan berbagai wilayah di negara lain. Beberapa metode pengambilan sampel biota perairan yang digunakan dalam penelitian terdahulu yaitu menggunakan trawl atau pukat dasar (jaring polietilen), jaring pukat pantai (10 m x 1,5 m; ukuran mata jaring: $8 \mathrm{~mm}$ ). Identifikasi MP pada saluran pencernakan biota ikan dilakukan menggunakan larutan $\mathrm{KOH} 10 \%$ selama 24 jam pada suhu $60^{\circ} \mathrm{C}$, selanjutnya dilakukan penyaringan dengan kertas saring Whatman. Selanjutnya, proses identifikasi menggunakan mikroskop okuler dan FTIR untuk menentukan ukuran, bentuk, dan jenis polimer. Hasil kajian menunjukkan bahwa kelimpahan MP terbanyak pada biota perairan masing-masing yaitu 468 partikel MP/individu pada spesies Ikan Sapu-Sapu (Hypostomus plecostomus) di perairan sungai; 18 partikel MP/individu pada Ikan Nila Hitam (Oreochromis niloticus) di perairan payau; 1,4 - 7 partikel MP/individu pada spesies Tiram (Saccostrea cucullata) di perairan muara; 22,21 \pm 1,7 partikel MP/individu pada spesies Ikan Thryssa kammalensis di perairan teluk; 2,7 \pm 0,10 partikel MP/individu pada spesies Ikan Zeus faber di perairan selat; dan 22,3 partikel MP/individu pada Diadema sp. (Bulu babi) di perairan laut. MP yang dominan pada biota perairan adalah berukuran $20 \mu \mathrm{m}-50 \mu \mathrm{m}$, berbentuk fiber, dan berwarna hitam. Polyethylene (PE) ditemukan dominan pada biota perairan permukaan, serta polyprophylene (PP) dan polyethylene (PE) pada biota perairan laut.
\end{abstract}

Kata Kunci: Bentuk, jenis polimer, ukuran, warna

\section{ABSTRACT}

Plastic wastes could be degraded into microplastic (MP) and nanoplastic (NP) through physical, chemical, and biological processes. MP was defined as the small particle of plastic with the size of $<5 \mathrm{~mm}$. Currently, MP has been found in the body of aquatic biota both in the surface and sea water biota. This research aimed to investigate the microplastic content in aquatic biota. The study was conducted through literature review of the last 10 year published articles. The previous studies were reviewed in terms of abundance, size, shape, colour, and polymer type of MP in the aquatic biota in Indonesia and areas of other countries. Sampling of aquatic biota in the previous studies was conducted in several methods using trawling or bottom trawl (polyethylene net), beach trawl net (10 m x 1.5 $\mathrm{m}$; mesh size: $8 \mathrm{~mm}$ ). Identification of MP in the digestive tract of fish was conducted using $10 \% \mathrm{KOH}$ solution for 24 hours at a temperature of $60^{\circ} \mathrm{C}$, then was filtered using Whatman filter paper. Next, the identification process used an ocular microscope and FTIR to determine the polymer. The result demonstrated that the highest number of MP abundance was 468 MP particles/individual in the cattle fish (Hypostomus plecostomus) species in the river water; 18 MP particles/individual in the black nile fish (Oreochromis niloticus) species in the brackish water; 1.4 - 7 MP particles/individual in the oyster (Saccostrea cucullata) species in the estuary water; $22.21 \pm 1.7 \mathrm{MP}$ particles/individual in the Thryssa kammalensis fish species in the gulf water; $2.7 \pm 0.10 \mathrm{MP}$ particles/individual in the Zeus faber fish species in the strait water; and 22.3 MP particles/individual in the Diadema sp. (sea urchin) in the sea water. The most dominant MP size, shape, and colour in the aquatic biota was $20 \mu \mathrm{m}-50 \mu \mathrm{m}$, fiber, and black. Polyethylene (PE) was dominant in the surface water biota, whereas, polyprophylene (PP) and polyethylene (PE) in the sea water biota.

Keywords: colour, polymer type, shape, size

Citation: Sandra, S. W. dan Radityaningrum, A. D. (2021). Kajian Kelimpahan Mikroplastik di Biota Perairan. Jurnal Ilmu Lingkungan, $19(3), 638-648$, doi:10.14710/jil.19.3.638-648

\section{Pendahuluan}

Pencemaran sampah terutama dari bahan plastik, telah menyebar di perairan di seluruh dunia dan menjadi isu global saat ini (Hardesty et al., 2017). Produksi sampah plastik diperkirakan antara 4,8 hingga 12,7 juta metrik ton (MMT) yang masuk ke laut (Jambeck et al., 2015). Sampah plastik memiliki ketahanan dan sifat persisten, produksi yang terus meningkat serta tingkat pemulihan yang rendah yang menyebabkan akumulasi serpihan plastik di sepanjang garis pantai, permukaan

\footnotetext{
*Penulis korespondensi: dyah@itats.ac.id
} 
perairan, berbagai kedalaman perairan, serta sedimen (Barnes et al., 2009). Keberadaan sampah plastik di laut ditemukan dengan kelimpahan yang berbeda pada permukaan, tengah dan dasar laut (Firdaus et al., 2019). Jenis plastik dengan kepadatan yang berbeda mempengaruhi kelimpahannya di perairan laut (van Cauwenberghe et al., 2013). Sampah plastik di laut berasal dari kegiatan domestik dan industri (Jambeck et al., 2015)) serta rendahnya tingkat pengelolaan sampah (Lestari \& Trihadiningrum, 2019). Transpor sampah di perairan permukaan mempengaruhi keberadaan sampah di perairan laut (Lestari et al., 2020). Hal ini berpotensi terhadap terjadinya kontaminasi biota pada air permukaan dan laut oleh sampah, termasuk sampah plastik (Firdaus et al., 2019).

Plastik dapat mengalami degradasi menjadi partikel plastik yang berukuran lebih kecil, salah satunya adalah mikroplastik (MP) (Cole et al., 2011). Bahan plastik yang masuk ke lingkungan sebagai sampah plastik dapat menjadi MP dan nanoplastik (NP) melalui proses fisik, kimia, dan biologis (Galgani, 2015). Polimer plastik kurang dapat terurai secara biologis di wilyah perairan, termasuk sungai, namun mengalami degradasi menjadi bagian yang lebih kecil akibat radiasi UV dan arus air (Wijaya \& Trihadiningrum, 2019). MP berpotensi tersebar di permukaan air (Faure et al., 2015), sedimen pesisir (Browne et al., 2011), pasir pantai (Liebezeit \& Dubaish, 2012), sedimen air tawar (Castañeda et al., 2014), dan laut dalam (Woodall et al., 2014).

MP didefinisikan sebagai partikel plastik kecil berukuran kurang dari $5 \mathrm{~mm}$ (Lusher et al., 2017; Storck et al., 2015; Lippiat et al., 2013). Sumber MP dikelompokkan menjadi dua, yaitu primer dan sekunder (Ayun, 2019). MP primer merupakan MP yang telah didesain dan diproduksi dengan ukuran sekitar $5 \mathrm{~mm}$, seperti dalam produk-produk pembersih dan kecantikan, pellet untuk pakan hewan, bubuk resin, dan umpan produksi plastik (Ariskha, 2019). Sementara itu, MP sekunder berasal dari degradasi plastik yang lebih kecil setelah melalui proses fotodegradasi di lingkungan laut dan proses pelapukan limbah lainnya seperti kantong plastik yang dibuang atau seperti jaring ikan (Eriksen et al., 2014).

Keberadaan partikel MP mulai dari ukuran, bentuk maupun jenis polimernya di berbagai wilayah perairan dapat menyebabkan dampak negatif terhadap biota (Permatasari \& Radityaningrum, 2020). MP berpotensi untuk menyerap senyawa organik yang persisten di lingkungan, dan bersifat toksik jika MP tertelan oleh biota (Crawford dan Quinn, 2017). Selain itu, MP berpotensi menyebabkan pendarahan internal dan penyumbatan pada saluran pencernaan (Wright et al., 2013). Keberadaan MP pada biota juga dapat lebih lanjut memberikan efek negatif pada manusia dan biota lainnya dalam rantai makanan (Browne et al., 2011). Berdasarkan penelitian Hwang et al. (2019), PP berukuran $<20 \mu \mathrm{m}$ berpotensi meningkatkan produksi sitokin dari sel imun pada tubuh manusia. Kajian MP dalam biota perairan penting dilakukan karena berpotensi mengakibatkan efek negatif bagi manusia dan biota lainnya. Hasil kajian dapat bermanfaat dalam memberikan informasi tentang kelimpahan, bentuk, ukuran dan warna MP yang telah ditemukan dalam biota perairan akibat pencemaran sampah plastik. Hal ini dapat dijadikan referensi untuk pengelolaan sampah plastik di lingkungan perairan.

\section{Karakteristik MP}

\subsection{Kategori $M P$}

Karakteristik MP yang ditemukan di lingkungan bervariasi ditinjau dari ukuran, bentuk, warna dan jenis polimernya (Browne et al., 2011). Menurut Lippiat et al. (2013), plastik dapat dibagi berdasarkan ukurannya yaitu mega $(>100 \mathrm{~cm})$, makro $(>2,5-100 \mathrm{~cm})$, meso $(>5-$ $25 \mathrm{~mm})$, mikro $(1-5000 \mu \mathrm{m})$, dan nano $(<1 \mu \mathrm{m})$. MP primer cenderung memiliki bentuk yang sesuai seperti saat diproduksi, menunjukkan bentuk bulat atau berserat dan memiliki permukaan yang konsisten, sementara MP sekunder cenderung memiliki bentuk yang lebih acak dan karena itu lebih sulit untuk dikategorikan (Zubris \& Richards, 2005). Berdasarkan bentuknya, partikel MP dikategorikan menjadi fiber/filamen (tipis atau berserat, lurus), pellet (keras, partikel bulat), fragment (partikel plastik keras, bergerigi), foam (ringan, seperti spons), atau film (bidang tipis) (Ariskha, 2019).

\subsection{Bentuk dan Warna MP}

Fiber dapat berasal dari serat pakaian, tali-temali, dan alat penangkap ikan seperti jaring atau pancing (Nor \& Obbard, 2014). Pellet merupakan bahan baku pembuatan plastik yang dibuat langsung oleh pabrik, dimana jenis ini termasuk MP primer (Dewi et al., 2015), MP bentuk fragment merupakan MP sekunder yang berasal dari potongan plastik bersifat polimer kuat, seperti polypropylene, polyethylene, dan polystyrene (Mani et al., 2015). Sedangkan bentuk foam dapat berasal dari fragmentasi makroplastik, seperti styrofoam box, gelas mie instan, styrofoam kotak makanan (Faruqi, 2019). Bentuk film tergolong dalam MP sekunder yang terbentuk dari fragmentasi plastik seperti kantong plastik dan kemasan makanan (Lassen et al., 2015) dan biasanya berjenis polimer polietilen (Virsek et al., 2016). Granule/butiran pada umumnya tergolong ke dalam jenis MP primer seperti microbeads yang terdapat pada produk kebersihan, perawatan atau kosmetik (Zhang et al., 2017).

MP memiliki karakteristik warna yang berbeda (Browne et al., 2011). Berdasarkan warnanya, MP dapat dikategorikan menjadi enam kategori: biru, hitam, kuning, transparan, putih dan merah. Kategori biru mencakup warna biru, biru tua, biru muda, hijau tua dan hijau muda (Peng et al., 2017). 


\subsection{Jenis Polimer MP}

Jenis polimer atau komposisi plastik diantaranya adalah etilena-vinil asetat kopolymer (EVA), polipropilena (PP), polietilena tereftalat (PET), polivinil klorida (PVC), cellophane (CP), polivinil asetat (PVA) dan poliamida (PA), dimana polimer tersebut termasuk dalam polimer plastik utama yang diproduksi di seluruh dunia (Lithner et al., 2011). Polietilena (PE), polipropilena (PP), polivinil klorida (PVC), polistirena (PS) dan polietilena tereftalat (PET) yang memiliki densitas rendah dan tinggi, merupakan komposisi plastik sintetis yang paling banyak digunakan dan menjadi polutan di lingkungan pesisir dan laut (Andrady, 2011; Engler, 2012).

\section{Dampak MP pada Biota Perairan}

Keberadaan MP di perairan laut akan berdampak negatif bagi biota, baik secara langsung maupun tidak langsung (Thevenon dan Carrol, 2015; Wilcox et al., 2016). Sampah plastik yang berukuran besar, seperti benang pancing dan jaring seringkali menyebabkan hewan-hewan terbelit (Carr, 1987). Sampah plastik yang berukuran lebih kecil, seperti tutup botol, korek api, dan pellet plastik, dapat tertelan oleh organisme perairan dan menyebabkan penyumbatan usus serta potensi keracunan bahan kimia (Fry et al., 1987). Konsumsi plastik oleh biota perairan dapat menyebabkan pendarahan internal dan bisul, serta penyumbatan pada saluran pencernaan (Wright et al., 2013). Partikel MP juga berpotensi toksik bagi ikan, yaitu toksisitas fisik dan kimiawi, karena pada dasarnya MP menyerap zat adiktif dan monomer lain yang bersifat toksik (Browne et al., 2013). Selain itu, keberadaan MP di dalam tubuh ikan dapat menurunkan kebugaran ikan dan kemudian mengakibatkan kematian (Tosetto et al., 2017); (Wright et al., 2013). Dampak langsung MP yang masuk ke tubuh organisme laut dapat mengganggu kerja saluran pencernaan (Cole et al., 2013), sebagai vektor/pembawa bahan tambahan, dan juga bahan pencemar organik lain yang teradsorpsi pada MP (Teuten et al., 2009). Biota perairan yang menelan secara tidak langsung dapat melalui konsumsi mangsa yang terkontaminasi MP (Vandermeersch et al., 2015). Plastik juga berpotensi menyerap dan melepas bahan kimia berbahaya ke perairan sehingga berdampak buruk dalam sistem rantai makanan, sehingga terjadi biomagnifikasi (Teuten et al., 2009). Sampah MP dapat masuk ke dalam biota perairan, yang berpotensi mengganggu kesehatan manusia jika dikonsumsi melalui rantai makanan (Eriksen et al., 2014; Kole et al., 2017; Wright \& Kelly, 2017).

\section{Metode Penelitian}

Penelitian ini merupakan kajian literatur yang dilakukan dengan menelaah penelitian yang dilakukan oleh peneliti terdahulu, mengenai kelimpahan MP pada biota perairan. Kajian ini dilakukan terhadap biota perairan permukaan (sungai, payau, dan muara) dan perairan laut (teluk, selat, dan laut). Artikel ilmiah yang dikaji merupakan hasil penelitian yang telah dilakukan di Indonesia dan berbagai wilayah di negara lain, serta dipublikasikan mulai tahun 2002-2020. Analisis deskriptif dalam penelitian ini memuat konsentrasi/kelimpahan, ukuran, bentuk, warna, dan komposisi/polimer dari MP yang ditemukan pada biota perairan. Kecenderungan jenis biota berdasarkan makanan dan habitatnya terhadap kontaminasi MP yang ditemukan di dalam tubuhnya dikaji untuk menentukan pola pencemaran MP dalam biota perairan.

Pengambilan sampel biota perairan dapat dilakukan dengan beberapa cara, yaitu dapat dilakukan dengan menggunakan trawl atau pukat dasar (jaring polietilen), jaring pukat pantai $(10 \mathrm{~m} \times 1,5 \mathrm{~m}$; ukuran mata jaring: $8 \mathrm{~mm}$ ) pada biota (ikan) (Murphy et al., 2017; Vendel et al., 2017; Sun et al., 2019), serta menggunakan tujuh perangkap ikan standar dengan umpan ikan pada biota kepiting (Piarulli et al., 2019). Metode pengambilan sampel biota perairan permukaan dan laut disesuaikan dengan kebutuhan peneliti. Hal ini bertujuan agar sampel biota dapat mewakili biota wilayah perairan yang diteliti.

Metode identifikasi MP pada biota (ikan) yaitu saluran pencernaan didestruksi dengan larutan $\mathrm{KOH}$ $10 \%$ selama 24 jam pada suhu $60^{\circ} \mathrm{C}$, selanjutnya dilakukan penyaringan dengan kertas saring Whatman, kemudian proses identifikasi menggunakan mikroskop okuler (Yudhantari et al., 2019) dan FTIR untuk menentukan polimer. Menurut Boerger et al., (2010), rumus perhitungan kelimpahan MP pada biota perairan terdapat padap persamaan (1).

$$
\text { Kelimpahan }=\frac{\text { jumlah partikel mikroplastik }}{\text { jumlah } \text { ikan }} \ldots . .(1)
$$

\section{Hasil dan Pembahasan}

\subsection{Mikroplastik di Biota Perairan Permukaan}

Biota yang dikaji merupakan biota yang hidup di perairan sungai, payau, dan muara. Hasil kajian MP pada biota perairan permukaan dapat dilihat pada Tabel 1 . Kelimpahan MP tertinggi terdapat pada biota sungai sebanyak 468 partikel MP/individu, yang ditemukan pada saluran pencernaan spesies ikan Sapu-Sapu (Hypostomus plecostomus) di Daerah Aliran Sungai (DAS) Kali Krukut. Ikan Sapu-Sapu merupakan jenis hewan omnivora oportunistik (Dewi et al., 2020). Namun, menurut Chaicana \& Jongphadungkiet (2012) Ikan SapuSapu juga memangsa ikan-ikan kecil dan telur ikan. Ikan Sapu-Sapu hidup di dasar perairan, dengan memakan sisa-sisa pakan, alga, lumut, dan sisa-sisa biota mati yang berada di dasar perairan, termasuk limbah yang berada di kawasan perairan (Puspitasari et al., 2018). Selain itu, Ikan Sapu-Sapu termasuk salah satu jenis ikan invasive species, dimana dapat menjadi predator maupun 
kompetitor dalam habitat asli (Hill \& Lodge, 1999). Ikan Sapu-Sapu mampu hidup di dalam kolam, parit, got dan bahkan lingkungan yang sudah tercemar oleh limbah (Munandar \& Eurika, 2016). Akumulasi MP di dalam saluran pencernaan Ikan Sapu-Sapu di Kali Krukut tersebut diduga karena habitat dan perilaku makannya. Selain itu, DAS Kali Krukut berpotensi mengandung MP yang berasal dari kegiatan domestik (Prabowo, 2019).

Ukuran MP pada biota perairan permukaan berkisar dari $20 \mu \mathrm{m}-4504,16 \mu \mathrm{m}$. Keberagaman ukuran MP tersebut dapat disebabkan oleh tingkat pencemaran di setiap wilayah perairan yang berbeda-beda. Selain itu, plastik terdegradasi menjadi MP dengan ukuran yang bervariasi. Di perairan, salah satunya pada sungai, polimer plastik kurang dapat terurai secara biologis, melainkan terpecah-pecah menjadi bagian yang lebih kecil akibat radiasi UV dan arus air (Wijaya \& Trihadiningrum, 2019).

Bentuk MP yang ditemukan diantaranya adalah fiber, fragment, dan film. Warna transparan dan hitam paling banyak ditemukan di biota perairan permukaan. MP bentuk fiber menjadi MP yang mendominasi pada biota perairan permukaan. MP bentuk fiber dapat berasal dari serat sintetis, tali-temali, jaring ikan (Nor \& Obbard, 2014). Selain itu, fiber juga berasal dari serat sintetis kegiatan pencucian/laundry baik dari industri massal maupun dari industri rumah yang dapat menghasilkan konsentrasi yang tinggi untuk MP jenis fiber (Browne et al., 2008). Adapun MP bentuk fragment merupakan jenis MP sekunder yang berasal dari potongan plastik bersifat polimer kuat, seperti polypropylene, polyethylene, dan polystyrene (Mani et al., 2015). MP bentuk film merupakan MP sekunder yang terbentuk dari fragmentasi plastik seperti kantong plastik dan kemasan makanan (Lassen et al., 2015).

Jenis polimer MP yang dominan ditemukan dalam biota perairan permukaan adalah polyethylene (PE), MP jenis PE merupakan bahan utama penyusun sampah kantong dan wadah plastik (GESAMP, 2015). MP dapat tertelan oleh jenis biota perairan herbivora karena salah mangsa (Jantz et al., 2013); (Setälä et al., 2014). Sedangkan keberadaan MP di dalam biota perairan jenis karnivora dan omnivora di perairan permukaan diduga karena perilaku makan maupun dari rantai makanan. Biota karnivora dan omnivora perairan menelan MP secara tidak langsung melalui konsumsi mangsa makroinvertebrata air yang terkontaminasi MP (Vandermeersch et al., 2015). Makroinvertebrata air tersebut diduga mengkonsumsi MP (Hurley et al., 2017); (Imhof et al., 2017); (Scherer et al., 2017). MP dalam mangsa makroinvertebrata air, berpotensi masuk ke dalam sistem pencernaan biota yang memangsanya. Dari kajian yang dilakukan, baik pada biota perairan yang hidup di permukaan, tengah, dan dasar perairan, MP cenderung dan dominan ditemukan pada saluran pencernaan. Namun, pada beberapa biota perairan MP juga ditemukan pada bagian tubuh yang lain seperti insang dan kulit. Sementara itu, MP yang terakumulasi pada biota perairan, baik dari jenis herbivora, karnivora, dan omnivora memiliki kelimpahan yang berbeda-beda. Hal ini dikarenakan tingkat pencemaran di wilayah perairan, perilaku biota serta habitat yang berbeda-beda.

\subsection{Mikroplastik di Biota Perairan Laut}

Habitat perairan laut yang dikaji dalam penelitian ini yaitu perairan teluk, selat dan laut. Hasil kajian MP pada biota perairan laut dapat dilihat pada Tabel 2 . Kelimpahan MP tertinggi pada biota perairan laut, terdapat pada spesies ikan Thryssa kammalensis dengan kelimpahan 22,21 \pm 1,7 partikel MP/individu. Tertelannya MP pada spesies tersebut dapat disebabkan karena tercemarnya Sungai Linhong sebagai salah satu sungai terbesar di sepanjang Teluk Haizhou akibat kegiatan pengangkutan limbah domestik dan air limbah industri, dan sebagian besar plastik dapat dipindahkan ke Teluk Haizhou (Feng et al., 2019). Selain itu, hal ini diduga karena habitat Thryssa kammalensis adalah di muara, dimana merupakan tempat dengan kelimpahan MP yang tinggi (Feng et al., 2019). MP tersebut bisa masuk ke dalam tubuh biota karena salah mangsa (Jantz et al., 2013); (Setälä et al., 2014). Spesies ikan Thryssa kammalensis termasuk dalam kelompok karnivora, sehingga biota perairan tersebut menelan MP secara tidak langsung melalui konsumsi mangsa yang terkontaminasi MP (Vandermeersch et al., 2015). Berdasarkan hasil kajian, ukuran MP berkisar dari 0,1 $\mathrm{mm}-5 \mathrm{~mm}$. Keberagaman ukuran MP tersebut dapat disebabkan oleh tingkat pencemaran di setiap wilayah perairan yang berbeda-beda.

Bentuk MP yang ditemukan diantaranya fiber, fragment, dan film dengan warna ditemukan diantaranya hitam dan transparan merupakan yang paling melimpah. Bentuk fiber menjadi MP yang paling melimpah pada biota perairan laut. Hal yang sama juga terjadi pada biota perairan permukaan. Bentuk fiber biasanya berasal dari aktivitas masyarakat yang bekerja sebagai nelayan. Jaring ikan yang digunakan nelayan tersebut mengalami degradasi akibat gesekan, gelombang laut dan sinar UV kemudian terurai menjadi komponen yang lebih kecil yaitu fiber (Lolodo \& Nugraha, 2019). Sementara itu, MP bentuk fragment pada dasarnya berasal dari sampah plastik yang terbuang ke perairan, kemudian mengalami penguraian menjadi serpihan-serpihan kecil hingga membentuk fragment (Dewi et al., 2015). Jenis polimer MP yang dominan ditemukan dalam biota perairan laut yaitu polyprophylene (PP) dan polyethylene (PE). Dari kajian yang dilakukan pada biota perairan laut (teluk, muara, dan laut), MP cenderung dan dominan ditemukan pada saluran pencernaan. Namun pada beberapa biota perairan juga ditemukan pada bagian tubuh yang lain seperti insang dan kulit. 
Tabel 1. Mikroplastik pada Biota Perairan Permukaan di Berbagai Lokasi

\begin{tabular}{|c|c|c|c|c|c|}
\hline Jenis Perairan & Jenis Biota & $\begin{array}{l}\text { Hidup di } \\
\text { Perairan }\end{array}$ & $\begin{array}{l}\text { Kelompok } \\
\text { Biota }\end{array}$ & Kelimpahan MP & Sumber \\
\hline \multicolumn{6}{|l|}{ Biota Sungai } \\
\hline DAS Kali Krukut, Jakarta & $\begin{array}{l}\text { Ikan Sapu-Sapu } \\
\text { (Hypostomus } \\
\text { plecostomus) }\end{array}$ & Dasar & Omnivora & 468 partikel MP/ind & Prabowo, (2019) \\
\hline Sungai Flemish, Belgia & $\begin{array}{l}\begin{array}{l}\text { Ikan liar } \\
\text { gudgeon } \\
\text { gobio) }\end{array} \\
\text { (Gobio }\end{array}$ & Dasar & Karnivora & 16 partikel MP & $\begin{array}{l}\text { Slootmaekers et al., } \\
\text { (2019) }\end{array}$ \\
\hline \multicolumn{6}{|l|}{ Biota Payau } \\
\hline Perairan Payau, Semarang & $\begin{array}{l}\text { Ikan Nila Hitam } \\
\text { (Oreochromis } \\
\text { niloticus) }\end{array}$ & Permukaan & Omnivora & 18 partikel MP/ind & Ratnasari, (2017) \\
\hline Tambak Lorok, Semarang & $\begin{array}{l}\text { Kerang Darah } \\
\text { (Anadara granosa) }\end{array}$ & Dasar & Omnivora & 12 partikel MP/ind & Fitri, (2017) \\
\hline Tambak Ngebruk, Semarang & $\begin{array}{l}\text { Ikan Belanak (Mugil } \\
\text { cephalus) }\end{array}$ & Dasar & Karnivora & 12 partikel MP/ind & Masanti, (2017) \\
\hline \multicolumn{6}{|l|}{ Biota Muara } \\
\hline Muara sungai Pearl, China & $\begin{array}{l}\text { Tiram (Saccostrea } \\
\text { cucullata) }\end{array}$ & Dasar & Omnivora & 1,4-7 partikel MP/ind & Li et al., (2018) \\
\hline \multirow[t]{2}{*}{$\begin{array}{l}\text { Muara Tropis Brasil (Paraiba } \\
\text { dan Mamanguape) }\end{array}$} & $\begin{array}{ll}\text { Ikan } & \text { Teri } \\
\text { (Lycengraulis } & \\
\text { grossidens) } & \end{array}$ & Permukaan & Karnivora & $0,20 \mathrm{MP} /$ ind & $\begin{array}{l}\text { Vendel et al., } \\
\text { (2017) }\end{array}$ \\
\hline & $\begin{array}{ll}\text { Ikan } & \text { Diapterus } \\
\text { auratus } & \end{array}$ & Permukaan & Karnivora & $0,97 \mathrm{MP} /$ ind & \\
\hline
\end{tabular}

Tabel 1 menunjukkan bahwa kelimpahan MP di biota perairan permukaan bervariasi. Hal ini dapat disebabkan karena tingkat pencemaran MP di setiap wilayah perairan dapat berbeda-beda. Selain itu, topografi, morfologi, dan klimatologi dari DAS pada lokasi studi juga mempengaruhi distribusi sampah plastik perairan permukaan serta perilaku biota (Lestari et al., 2020). di Biota omnivora memiliki kecenderungan ditemukan MP dengan kelimpahan yang besar. Hal ini disebabkan karena perilaku biota omnivora dalam memangsa makanannya (Ariyanto, 2002). Namun, hal tersebut berbeda dengan biota omnivora tiram yang hidup di muara. Kelimpahan MP di dalam tiram ditemukan dalam jumlah yang sedikit. Hal ini diduga karena biota tiram merupakan jenis biota yang diam, sehingga potensi bertemunya tiram dengan pencemar MP lebih sedikit daripada jenis biota bergerak. Oleh karenanya potensi biota tiram mengalami salah mangsa lebih kecil daripada jenis biota bergerak (Muchlisin, 2010).

Uji statistik dilakukan terhadap kelimpahan MP pada biota perairan permukaan berdasarkan klasifikasi habitatnya (biota sungai, payau, dan muara). Berdasarkan analisis statistik non parametrik dengan Uji Kruskal-Wallis, diperoleh nilai signifikansi $>0,05(0,06)$. Hal ini menunjukkan bahwa tidak terdapat perbedaan yang signifikan terhadap kelimpahan MP pada biota air permukaan berdasarkan klasifikasi habitatnya.
Berdasarkan Tabel 2, kelimpahan MP di biota perairan laut memiliki hasil bervariasi. Hal ini dapat disebabkan karena tingkat pencemaran MP di habitat perairan yang diteliti berbeda-beda. Hal ini dapat dilihat pada penelitian Yumni et al., (2020), dimana pada ikan Tongkol (Euthynnus affinis) dan Dencis (Sardinella lemuru), tidak ditemukan kandungan MP. Hal ini disebabkan oleh keadaan laut yang bersih dan tidak banyak polusi sampah plastik di laut Aceh (Yumni et al., 2020). Selain itu, hasil keberadaan MP yang tidak ditemukan pada ikan tongkol dan ikan dencis dipengaruhi oleh gaya hidup ikan yang berbeda-beda. Ikan tongkol memiliki kebiasaan sering bergerombol dengan berbagai jenis ikan dengan ukuran tubuh yang sama, adapun makanan ikan tongkol berasal dari aneka jenis ikan, udang, dan kerabat cumi-cumi (Yumni et al., 2020). Sementara ikan dencis memiliki sifat pelagis dan hidup berkelompok, berada di dekat permukaan dan dekat pantai, dengan makanan berupa plankton (Yumni et al., 2020). Kebiasaan makan ikan di zona pelagis menyebabkan termakannya MP, namun karena laut tidak tercemar sampah plastik maka ikan secara tidak langsung tidak menelan MP (Claessens et al., 2013). Berbeda dengan penelitian yang dilakukan oleh Feng et al., (2019), dimana spesies ikan Thryssa kammalensis memiliki kelimpahan MP yang cukup tinggi. Hal ini disebabkan sungai Linhong yang merupakan salah satu sungai darat terbesar di Teluk 
Haizhou, mengangkut 2,26×108 ton limbah domestik dan limbah industri pada 2010 dan sebagian besar plastik dapat dipindahkan ke Teluk Haizhou (EPAL, 2011). Semakin tinggi sampah plastik pada lingkungan, maka semakin tinggi pula potensi pencemaran lingkungan yang berdampak bahaya bagi ekosistem alam, termasuk biota dan manusia yang hidup dalam ekosistem (Law \& Thompson, 2014). MP pada biota perairan laut berdasarkan habitatnya diuji statistik non parametrik dengan Uji Kruskal-Wallis. Hasil uji menghasilkan nilai signifikansi >0,05 $(0,09)$. Kelimpahan MP pada biota perairan laut berdasarkan klasifikasi teluk, selat, dan laut tidak memiliki perbedaan yang signifikan. Adapun variasi bentuk dan warna MP hasil penelitian oleh peneliti terdahulu dalam kajian ini ditunjukkan dalam Gambar 1 dan 2.

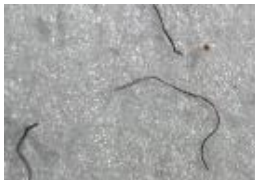

A. Fiber

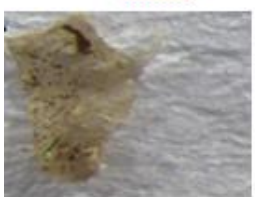

D. Film

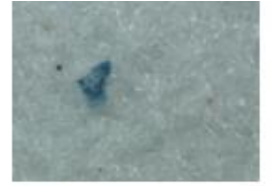

B. Fragment

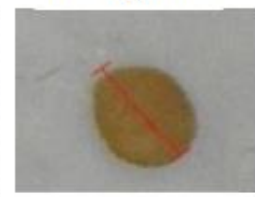

E. Granule

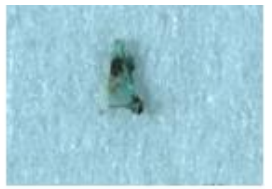

C. Sheet

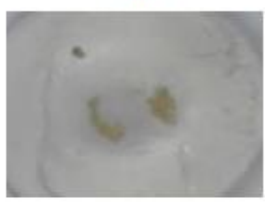

F. Pellet

Gambar 1 Bentuk MP: A. Fiber; B. Fragment; C. Sheet; D. Film; E. Granule; F. Pellet

(Sumber: Feng et al., 2019; Baalkhuyur et al., 2018; Faruqi, 2019)

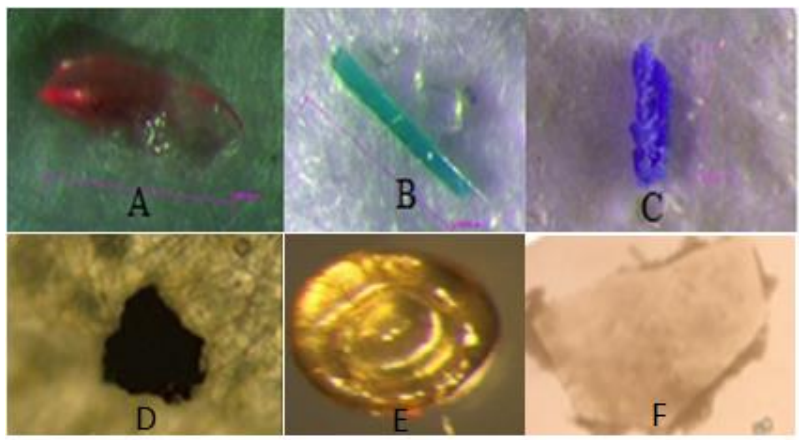

Gambar 2 Warna MP: A. Merah; B. Hijau; C. Biru; D. Hitam; E. Kuning; F. Putih/Transparan

(Sumber: Digka et al., 2018; Ismail et al., 2019; Cole et al., 2014; Hossain et al., 2019)

Tabel 2. Mikroplastik pada Biota Perairan Laut di Berbagai Lokasi

\begin{tabular}{|c|c|c|c|c|c|}
\hline Perairan & Jenis Biota & $\begin{array}{l}\text { Hidup di } \\
\text { Perairan }\end{array}$ & $\begin{array}{l}\text { Kelompok } \\
\text { Biota }\end{array}$ & Kelimpahan MP & Sumber \\
\hline \multicolumn{6}{|l|}{ Teluk } \\
\hline Pangandaran, & $\begin{array}{l}\text { Ikan Trichiurus sp. dan } \\
\text { Johnius sp. }\end{array}$ & Tengah & Karnivora & 193 partikel MP & Ismail et al., (2019) \\
\hline Teluk Haizhou, China & $\begin{array}{l}\text { Ikan Thryssa kammalensis } \\
\text { Ikan Cynoglossus semilaevis }\end{array}$ & $\begin{array}{l}\text { Tengah } \\
\text { Dasar }\end{array}$ & $\begin{array}{l}\text { Karnivora } \\
\text { Karnivora }\end{array}$ & $\begin{array}{l}22,21 \pm 1,70 \mathrm{MP} / \text { ind } \\
13,54 \pm 2,09 \mathrm{MP} / \text { ind }\end{array}$ & Feng et al., (2019) \\
\hline \multirow[t]{2}{*}{ Teluk Singa } & $\begin{array}{l}\text { Ikan Sarden } \quad \text { (Sardina } \\
\text { pilchardus) }\end{array}$ & Permukaan & Karnivora & $0,20 \pm 0,69 \mathrm{MP} /$ ind & \multirow[t]{2}{*}{ Lefebvre et al., (2019) } \\
\hline & $\begin{array}{l}\text { Ikan Teri } \quad \text { (Engraulis } \\
\text { encrasicolus) }\end{array}$ & Permukaan & Karnivora & $0,11 \pm 0,31 \mathrm{MP} /$ ind & \\
\hline \multirow{2}{*}{$\begin{array}{l}\text { Teluk Utara Bengal, } \\
\text { Bangladesh }\end{array}$} & Ikan Harpadon translucens & Dasar & Karnivora & $5,80 \pm 1,41 \mathrm{MP} /$ ind & \multirow[t]{2}{*}{ Hossain et al., (2019) } \\
\hline & $\begin{array}{l}\text { Ikan Harpadon neherus } \\
\text { Ikan Sardinella gibbosa }\end{array}$ & $\begin{array}{c}\text { Dasar } \\
\text { Permukaan }\end{array}$ & $\begin{array}{l}\text { Karnivora } \\
\text { Karnivora }\end{array}$ & $\begin{array}{l}8,72 \pm 1,54 \mathrm{MP} / \text { ind } \\
3,20 \pm 1,16 \mathrm{MP} / \text { ind }\end{array}$ & \\
\hline Teluk Meksiko & Ikan tawar dan ikan laut & - & - & - & $\begin{array}{l}\text { Phillips \& Bonner, } \\
\text { (2015) }\end{array}$ \\
\hline
\end{tabular}




\begin{tabular}{|c|c|c|c|c|c|}
\hline Perairan & Jenis Biota & $\begin{array}{l}\text { Hidup di } \\
\text { Perairan }\end{array}$ & $\begin{array}{l}\text { Kelompok } \\
\text { Biota }\end{array}$ & Kelimpahan MP & Sumber \\
\hline \multirow{2}{*}{$\begin{array}{l}\text { Padang Lamun Kepulauan } \\
\text { Spermonde, Makassar }\end{array}$} & Tiram (Pinctada sp.) & Dasar & Omnivora & $0,08 \mathrm{MP} /$ ind & \multirow[t]{2}{*}{ Sari, (2018) } \\
\hline & $\begin{array}{l}\text { Tiram (Pinna mucirata) } \\
\text { Tiram (Malleus sp.) }\end{array}$ & $\begin{array}{l}\text { Dasar } \\
\text { Dasar }\end{array}$ & $\begin{array}{l}\text { Omnivora } \\
\text { Omnivora }\end{array}$ & $\begin{array}{l}0,25 \mathrm{MP} / \text { ind } \\
0,125 \mathrm{MP} / \text { ind }\end{array}$ & \\
\hline \multicolumn{6}{|c|}{ 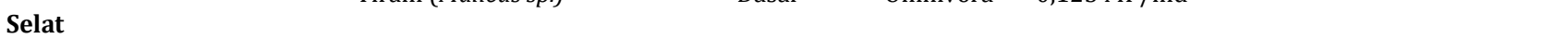 } \\
\hline Selat Bali & $\begin{array}{l}\text { Ikan Lemuru Protolan } \\
\text { (Sardinella lemuru) }\end{array}$ & Permukaan & Karnivora & $1 \mathrm{MP} /$ ind & $\begin{array}{l}\text { Yudhantari et al., } \\
\text { (2019) }\end{array}$ \\
\hline Selat Inggris & $\begin{array}{l}\text { Ikan John dory zeus faber } \\
\text { Ikan Trisopterus minutus } \\
\text { Ikan Merlangius merlagus }\end{array}$ & $\begin{array}{l}\text { Permukaan } \\
\text { Permukaan } \\
\text { Permukaan }\end{array}$ & $\begin{array}{l}\text { Karnivora } \\
\text { Karnivora } \\
\text { Karnivora }\end{array}$ & $\begin{array}{l}2,7 \pm 0,10 \mathrm{MP} / \text { ind } \\
2,0 \pm 0,10 \mathrm{MP} / \text { ind } \\
1,75 \pm 0,10 \mathrm{MP} / \text { ind }\end{array}$ & Lusher et al., (2013) \\
\hline $\begin{array}{l}\text { Selat Adriatik Utara, Italia } \\
\text { Laut }\end{array}$ & \multicolumn{4}{|c|}{ Laut } & Piarulli et al., (2019) \\
\hline $\begin{array}{l}\text { Daratan Terumbu Pulau Gili } \\
\text { Labak, Sumenep }\end{array}$ & Bulu babi (Diadema sp.) & Dasar & Herbivora & 22,3 MP/ind & $\begin{array}{l}\text { Lolodo \& Nugraha, } \\
\text { (2019) }\end{array}$ \\
\hline \multirow[t]{3}{*}{ Pulau Mandangin, Sampang } & Ikan Kerapu (Ephinepelus) & Dasar & Karnivora & $1-3 \mathrm{MP} /$ ind & \multirow[t]{3}{*}{ Rahmadhani, (2019) } \\
\hline & $\begin{array}{l}\text { Ikan Kerisi Merah } \\
\text { (Nemiptenus) }\end{array}$ & Dasar & Karnivora & 1-6 MP/ind & \\
\hline & $\begin{array}{l}\text { Ikan Tongkol (Euthynnus) } \\
\text { Ikan Lemuru (Sardinella) }\end{array}$ & $\begin{array}{l}\text { Permukaan } \\
\text { Permukaan }\end{array}$ & $\begin{array}{l}\text { Karnivora } \\
\text { Karnivora }\end{array}$ & $\begin{array}{l}\text { 2-5 MP/ind } \\
\text { 3-5 MP/ind }\end{array}$ & \\
\hline \multirow[t]{2}{*}{ TPI Lampulo, Banda Aceh } & $\begin{array}{l}\text { Ikan Tongkol (Euthynnus } \\
\text { affinis) }\end{array}$ & Permukaan & Karnivora & - & \multirow[t]{2}{*}{ Yumni et al., (2020) } \\
\hline & $\begin{array}{l}\text { Ikan Dencis (Sardinella } \\
\text { lemuru) }\end{array}$ & Permukaan & Karnivora & - & \\
\hline $\begin{array}{l}\text { Perairan Pesisir Laut Utara } \\
\text { bagian Selatan (Perancis, } \\
\text { Belgia, Belanda, dan Inggris) }\end{array}$ & $\begin{array}{l}\text { Udang coklat (Crangon } \\
\text { crangon) }\end{array}$ & Permukaan & Omnivora & $1,23 \pm 0,99 \mathrm{MP} /$ udang & Devriese et al., (2015) \\
\hline \multirow[t]{3}{*}{ Laut Kuning, China } & Ikan Enchelyopus elongates & Tengah & Omnivora & 1,2 MP/ind & \multirow[t]{3}{*}{ Sun et al., (2019) } \\
\hline & Ikan Gadus macrocephalus & Tengah & Omnivora & $1,1 \mathrm{MP} /$ ind & \\
\hline & Ikan Ammodytes personatus & Tengah & Omnivora & 1,4 MP/ind & \\
\hline \multirow[t]{3}{*}{ Laut Merah, Arab Saudi } & Ikan Acanthurus gahhm & Dasar & Karnivora & $1 \mathrm{MP} / \mathrm{ind}$ & \multirow{3}{*}{$\begin{array}{l}\text { Baalkhuyur et al., } \\
(2018)\end{array}$} \\
\hline & Ikan Epinephelus areolatus & Dasar & Karnivora & $1 \mathrm{MP} / \mathrm{ind}$ & \\
\hline & $\begin{array}{ll}\text { Ikan } & \text { Pristipomoides } \\
\text { multidens } & \end{array}$ & Tengah & Karnivora & $2 \mathrm{MP} / \mathrm{ind}$ & \\
\hline \multirow[t]{2}{*}{ Lepas Pantai Portugis } & Ikan Alosa fallax & Permukaan & Karnivora & $1 \mathrm{MP} /$ ind & \multirow[t]{2}{*}{ Neves et al., (2015) } \\
\hline & $\begin{array}{l}\text { Ikan Argyrosomus regius } \\
\text { Ikan Boops boops }\end{array}$ & $\begin{array}{l}\text { Dasar } \\
\text { Dasar }\end{array}$ & $\begin{array}{l}\text { Karnivora } \\
\text { Karnivora }\end{array}$ & $\begin{array}{l}0,80 \pm 0,8 \mathrm{MP} / \text { ind } \\
0,09 \pm 0,3 \mathrm{MP} / \text { ind }\end{array}$ & \\
\hline \multirow{5}{*}{$\begin{array}{l}\text { Lepas Pantai Perairan } \\
\text { Skotlandia Atlantik Timur } \\
\text { Laut }\end{array}$} & & & & & \\
\hline & Ikan Pleuronectes platessa & Dasar & Omnivora & $0,9 \pm 1,79 \mathrm{MP} /$ ind & \multirow[t]{4}{*}{ Murphy et al., (2017) } \\
\hline & Ikan Platichthys flesus & Dasar & Omnivora & $0,8 \pm 0,94 \mathrm{MP} /$ ind & \\
\hline & Ikan Limanda limanda & Dasar & Omnivora & $1,3 \pm 1,67 \mathrm{MP} /$ ind & \\
\hline & $\begin{array}{l}\text { Ikan Lepidorhombus } \\
\text { whiffiagonis }\end{array}$ & Dasar & Karnivora & $0,1 \pm 0,32 \mathrm{MP} /$ ind & \\
\hline \multirow[t]{4}{*}{$\begin{array}{l}\text { Laut Ionia Utara (Laut } \\
\text { Mediterania) }\end{array}$} & $\begin{array}{ll}\begin{array}{l}\text { Kerang } \\
\text { galloprovincialis) }\end{array} & \text { (Mytilus }\end{array}$ & Dasar & Omnivora & $1,7 \pm 0,2 \mathrm{MP} /$ ind & \multirow[t]{4}{*}{ Digka et al., (2018) } \\
\hline & $\begin{array}{l}\text { Ikan Sarden (Sardina } \\
\text { pilchardus) }\end{array}$ & Permukaan & Omnivora & $1,8 \pm 0,2 \mathrm{MP} /$ ind & \\
\hline & $\begin{array}{l}\text { Ikan Pandora umum } \\
\text { (Pagellus erythrinus) }\end{array}$ & Dasar & Karnivora & $1,9 \pm 0,2 \mathrm{MP} /$ ind & \\
\hline & $\begin{array}{l}\text { Ikan Belanak merah (Mullus } \\
\text { barbatus) }\end{array}$ & Dasar & Karnivora & $1,5 \pm 0,3 \mathrm{MP} /$ ind & \\
\hline \multirow[t]{2}{*}{$\begin{array}{l}\text { Pantai Ancol, } \\
\text { Pelabuhanratu, dan Labuan }\end{array}$} & Ikan Kakap (Lutjanus $s p$ ) & Dasar & Karnivora & $10 \mathrm{MP} /$ ind & \multirow[t]{2}{*}{ Hapitasari et al., (2016) } \\
\hline & $\begin{array}{l}\text { Ikan Kerapu (Epinephelus } \\
\text { sp) }\end{array}$ & Dasar & Karnivora & & \\
\hline \multirow[t]{4}{*}{ Laut Utara Belanda } & $\begin{array}{l}\text { Periwinkle } \quad \text { (Littorina } \\
\text { littorea) }\end{array}$ & Dasar & Omnivora & $20 \mathrm{MP} /$ ind & \multirow[t]{4}{*}{ Leslie et al., (2017) } \\
\hline & $\begin{array}{l}\text { Hopper pasir (Gammarus } \\
s p \text { ) }\end{array}$ & Dasar & Omnivora & $11 \mathrm{MP} /$ ind & \\
\hline & $\begin{array}{l}\text { Tiram pasifik (Crassostrea } \\
\text { gigas) }\end{array}$ & Dasar & Omnivora & $87 \mathrm{MP} /$ ind & \\
\hline & Mussel biru (Mytilus edulis) & Dasar & Omnivora & $105 \mathrm{MP} /$ ind & \\
\hline Great Barrier Reef, Australia & $\begin{array}{l}\text { Penyu hijau (Chelonia } \\
\text { mydas) }\end{array}$ & Pesisir & Omnivora & $3 \mathrm{MP} /$ ind & Caron et al., (2018) \\
\hline
\end{tabular}

Sumber: data diolah dari hasil studi literature 


\section{Kesimpulan}

Kelimpahan MP terbanyak pada biota perairan yaitu 468 partikel MP pada spesies ikan Sapu-Sapu (Hypostomus plecostomus) di perairan sungai; 18 partikel MP/individu pada ikan Nila Hitam (Oreochromis niloticus) di perairan payau; 1,4 - 7 partikel MP/individu pada spesies Tiram (Saccostrea cucullata) di perairan muara; 22,21 \pm 1,7 partikel MP/individu pada spesies ikan Thryssa kammalensis di perairan teluk; 2,7 $\pm 0,10$ partikel MP/individu pada spesies ikan Zeus faber di perairan selat; dan 22,3 partikel MP/individu pada Diadema sp. (Bulu Babi) di perairan laut. Ukuran MP dominan ditemukan pada biota perairan adalah $20 \mu \mathrm{m}-50 \mu \mathrm{m}$. Bentuk dan warna MP yang dominan ditemukan pada biota perairan permukaan dan perairan laut adalah fiber dan berwarna hitam. Sedangkan jenis polimer MP yang dominan ditemukan adalah polyethylene (PE) pada biota perairan permukaan, serta polyprophylene (PP) dan polyethylene (PE) pada biota perairan laut.

\section{DAFTAR PUSTAKA}

Andrady, A. L. 2011. Microplastics in the marine environment. Marine Pollution Bulletin, 62(8), 15961605.

Ariskha, P. T. 2019. Studi Kandungan Micro Debris Pada Sistem Distribusi Air Minum Daerah Surabaya Timur Di IPAM Ngagel III. Skripsi, Institut Teknologi Sepuluh Nopember. Surabaya.

Ariyanto, D. 2002. Analisis keragaman bentuk tubuh ikan nila strain gift pada tingkatan umur yang berbeda. Jurnal Perikanan Universitas Gadjah Mada, 4(1), 19 26.

Ayun, N. Q. 2019. Analisis Mikroplastik Menggunakan FT-IR Pada Air, Sedimen, Dan Ikan Belanak (Mugil cephalus) Di Segmen Sungai Bengawan Solo Yang Melintasi Kabupaten Gresik. Skripsi, Universitas Islam Negeri Sunan Ampel Surabaya.

Baalkhuyur, F. M., Bin Dohaish, E. J. A., Elhalwagy, M. E. A., Alikunhi, N. M., AlSuwailem, A. M., Røstad, A., Coker, D. J., Berumen, M. L., \& Duarte, C. M. 2018. Microplastic in the gastrointestinal tract of fishes along the Saudi Arabian Red Sea coast. Marine Pollution Bulletin, 131, 407-415.

Barnes, D. K. A., Galgani, F., Thompson, R. C., \& Barlaz, M. 2009. Accumulation and fragmentation of plastic debris in global environments. Philosophical Transactions of the Royal Society B: Biological Sciences, 364(1526), 1985-1998.

Boerger C.M., Lattin G.L., Moore S.L., Moore C.J. 2010. Plastic ingestion by planktivorous fishes in the North Pacific Central Gyre. Marine Pollution Bulletin, 60, 2275-2278.

Browne, M. A., Niven, S. J., Galloway, T. S., Rowland, S. J., \& Thompson, R. C. 2013. Microplastic Moves Pollutants and Additives to Worms, Reducing Functions Linked to Health and Biodiversity. Current Biology, 23(23), 2388-2392.

Browne, M. A., Crump, P., Niven, S. J., Teuten, E., Tonkin, A.,
Galloway, T., \& Thompson, R. 2011. Accumulation of microplastic on shorelines woldwide: sources and sinks. Environmental Science and Technology, 45(21), 9175-9179.

Browne, M. A., Dissanayake, A., Galloway, T. ., Lowe, D. ., \& Thompson, R. . 2008. Ingested Microscopic Plastic Translocates to the Circulatory System of the Mussel, Mytilus edulis (L.). Environmental Science and Technology, 42(13), 5026-5031.

Caron, A. G. M., Thomas, C. R., Berry, K. L. E., Motti, C. A., Ariel, E., \& Brodie, J. E. 2018. Ingestion of microplastic debris by green sea turtles (Chelonia mydas) in the Great Barrier Reef: Validation of a sequential extraction protocol. Marine Pollution Bulletin, 127, 743-751.

Carr, A. 1987. Impact of Nondegradable Marine Debris on the Ecology and Survival Outlook of Sea Turtles. Marine Pollution Bulletin, 18(6B), 352-356.

Castañeda, R. A., Avlijas, S., Anouk Simard, M., \& Ricciardi, A. 2014. Microplastic pollution in St. Lawrence River sediments. Canadian Journal of Fisheries and Aquatic Sciences, 71(12), 1767-1771.

van Cauwenberghe, L., Vanreusel, A., Mees, J., Janssen, C.R. 2013. Microplastic pollution in deep-sea sediments. Environmental Pollution, 182, 495-499.

Chaichana, R., \& Jongphadungkiet, S. 2012. Assessment of the invasive catfish Pterygoplichthys pardalis (Castelnau, 1855) in Thailand: ecological impacts and biological control alternatives. Tropical Zoology, 25(4), 173-182.

Claessens, M., Van Cauwenberghe, L., Vandegehuchte, M. B., \& Janssen, C. R. 2013. New techniques for the detection of microplastics in sediments and field collected organisms. Marine Pollution Bulletin, 70(12), 227-233.

Cole, M., Webb, H., Lindeque, P. K., Fileman, E. S., Halsband, C., \& Galloway, T. S. 2014. Isolation of microplastics in biota-rich seawater samples and marine organisms. Scientific Reports, 4, 1-8.

Cole, M., Lindeque, P., Fileman, E., Halsband, C., Goodhead, R., Moger, J., \& Galloway, T. S. 2013. Microplastic ingestion by zooplankton. Environmental Science and Technology, 47(12), 6646-6655.

Cole, M., Lindeque, P., Halsband, C., \& Galloway, T. 2011. Microplastic as contaminants in the marine environment: a review. Marine Pollution Bulletin, 62(12), 2588-2597.

Crawford, C. B., Quinn, B. 2017. Microplastic Pollutant. Elsevier.

Devriese, L. I., van der Meulen, M. D., Maes, T., Bekaert, K., Paul-Pont, I., Frère, L., Robbens, J., \& Vethaak, A. D. 2015. Microplastic contamination in brown shrimp (Crangon crangon, Linnaeus 1758) from coastal waters of the Southern North Sea and Channel area. Marine Pollution Bulletin, 98(1-2), 179-187.

Dewi, I. S., Budiarsa, A. A., \& Ritonga, I. R. 2015. Distribusi mikroplastik pada sedimen di Muara Badak, Kabupaten Kutai Kartanegara. Depik, 4(3), 121-131.

Dewi, M., Suwarni, S., \& Omar, S. B. A. 2020. Kebiasaan Makanan Ikan Sapu-sapu (Pterygoplichthys Multiradiatus Hancock, 1828) di Perairan Danau Sidenreng, Kabupaten Sidenreng Rappang, Sulawesi Selatan. Prosiding Simposium Nasional VII Kelautan dan Perikanan, Universitas Hasanuddin.

Digka, N., Tsangaris, C., Torre, M., Anastasopoulou, A., \& Zeri, C. 2018. Microplastics in mussels and fish from the Northern Ionian Sea. Marine Pollution Bulletin, 135, 
30-40.

Engler, R. E. 2012. The Complex Interaction between Marine debris and Toxic Chemicals in the Ocean. Environmental Science and Technology, 46(22), 12302-12315.

EPAL (Environmental Protection Agency of Lianyungang), 2011. Environment Quality Bulletin of Lianyuangang in 2010. Environmental Protection Agency of Lianyuangang (in Chinese).

Eriksen, M., Lebreton, L. C. M., Carson, H. S., Thiel, M., Moore, C. J., Borerro, J. C., Galgani, F., Ryan, P. G., \& Reisser, J. 2014. Plastic Pollution in the World's Oceans: More than 5 Trillion Plastic Pieces Weighing over 250,000 Tons Afloat at Sea. PLoS ONE, 9(12), 1-15.

Faruqi, H. M. 2019. Persebaran Komposisi dan Kelimpahan Mikroplastik di Kali Surabaya Segmen Driyorejo. Skripsi, Universitas Airlangga.

Faure, F., Demars, C., Wieser, O., Kunz, M., \& de Alencastro, L. F. 2015. Plastic pollution in Swiss surface waters: nature and concentrations, interaction with pollutants. Environmental Chemistry, 12, 582-591.

Feng, Z., Zhang, T., Li, Y., He, X., Wang, R., Xu, J., \& Gao, G. 2019. The accumulation of microplastics in fish from an important fish farm and mariculture area, Haizhou Bay, China. Science of the Total Environment, 696, 133948.

Firdaus, M., Trihadiningrum, Y., Lestari, P. 2019. Microplastic pollution in the sediment of Jagir Estuary, Surabaya City, Indonesia. Marine Pollution Bulletin, 150, 110790.

Fitri, I. A. 2017. Studi Awal Mikroplastik Pada Kerang Darah (Anadara granosa) dari Tambak Lorok Semarang. Skripsi, Universitas Katolik Soegijapranata Semarang.

Fry, D. M., Fefer, S. I., \& Sileo, L. 1987. Ingestion of Plastic Debris by Laysan Albatrosses and Wedge-tailed Shearwaters in the Hawaiian Islands. Marine Pollution Bulletin, 18(6B), 339-343.

Galgani, F. 2015. The Mediterranean Sea: From litter to microplastics. MICRO2015, 15.

GESAMP, 2015. Sources, fate and effects of microplastics in the marine environment: a global assessment. In: Kershaw, P.J. (Ed.), (IMO/FAO/UNESCOIOC/UNIDO/WMO/IAEA/UN/UNEP/UNDP Joint Group of Experts on the ScientificAspects of Marine Environmental Protection). Rep. Stud. GESAMP No. 90, 96p.

Hapitasari, D. N., Farajallah, A., \& Mashar, A. 2016. Analisis Kandungan Mikroplastik pada Pasir dan Ikan Demersal: Kakap (Lutjanus Sp.) dan Kerapu (Epinephelus Sp.) di Pantai Ancol Pelabuhanratu dan Labuan. Skripsi. Institut Pertanian Bogor.

Hardesty, B. D., Harari, J., Isobe, A., Lebreton, L., Maximenko, N., Potemra, J., van Sebille, E., Dick Vethaak, A., \& Wilcox, C. 2017. Using numerical model simulations to improve the understanding of micro-plastic distribution and pathways in the marine environment. Frontiers in Marine Science, 4, 1-9.

Hill, A. M., \& Lodge, D. M. 1999. Replacement of resident crayfishes by an exotic crayfish: the roles of competition and predation. Ecological Application, 9(2), 678-690.

Hossain, M. S., Sobhan, F., Uddin, M. N., Sharifuzzaman, S. M., Chowdhury, S. R., Sarker, S., \& Chowdhury, M. S. N. 2019. Microplastics in fishes from the Northern Bay of Bengal. Science of the Total Environment, 690, 821-
830.

Hurley, R. R., Woodward, J. C., \& Rothwell, J. J. 2017. Ingestion of Microplastics by Freshwater Tubifex Worms. Environmental Science and Technology, 51(21), 12844-12851.

Hwang, J., Choi, D., Han, S., Choi, J., Hong, J. 2019. An assessment of the toxicity of polypropylene microplastics in human derived cells". Science of Total Environment, 684, 657-669.

Imhof, H. K., Rusek, J., Thiel, M., Wolinska, J., \& Laforsch, C. 2017. Do microplastic particles affect Daphnia magna at the morphological, life history and molecular level? PLOS ONE, 12(11), 1-20.

Ismail, M. R., Lewaru, M. W., \& Prihadi, D. J. 2019. Microplastics Ingestion by Fish inThe Pangandaran Bay, Indonesia. World News of Natural Sciences, 23, 173-181.

Jambeck, J., Geyer, R., Wilcox, C., Siegler, T. R., Perryman, M., Andrady, A., Narayan, R., \& Law, K. L. 2015. Plastic waste inputs from land into the ocean. Marine Pollution, 347(6223), 768.

Jantz, L. A., Morishige, C. L., Bruland, G. L., \& Lepczyk, C. A. 2013. Ingestion of plastic marine debris by longnose lancetfish (Alepisaurus ferox) in the North Pacific Ocean. Marine Pollution Bulletin, 69(1-2), 97-104.

Kole, P. J., Lohr, A. J., Van Belleghem, F. G. A. J., \& Ragas, A. M. J. 2017. Wear and tear of tyres: A stealthy source of microplastics in the environment. International Journal of Environmental Research and Public Health, 14(10), 2-31.

Lassen, C., Hansen, S. F., Magnusson, K., Hartmann, N. B., Rehne Jensen, P., Nielsen, T. G., \& Brinch, A. 2015. Microplastics Occurrence, effects and sources of releases to the environment Denmark. In Danish Environmental Protection Agency.

Law, K.L., \& R.C. Thompson. 2014. Microplastic in the seas. Science. 345: 144-145.

Lefebvre, C., Saraux, C., Heitz, O., Nowaczyk, A., \& Bonnet, D. 2019. Microplastics FTIR characterisation and distribution in the water column and digestive tracts of small pelagic fish in the Gulf of Lions. Marine Pollution Bulletin, 142, 510-519.

Leslie, H. A., Brandsma, S. H., van Velzen, M. J. M., \& Vethaak, A. D. 2017. Microplastics en route: Field measurements in the Dutch river delta and Amsterdam canals, wastewater treatment plants, North Sea sediments and biota. Environment International, 101, 133-142.

Lestari, P. dan Trihadiningrum, Y. 2019. The impact of improper solid waste management to plastic pollution in Indonesian coast and marine environment. Marine Pollution Bulletin, 149, 110505.

Lestari, P., Trihadiningrum, Y., Wijaya, B. A., Yunus, K. A., Firdaus, M. 2020. Distribution of microplastic in Surabaya River, Indonesia. Science of the Total Environment, 1016, 138560.

Li, H. X., Ma, L. S., Lin, L., Ni, Z. X., Xu, X. R., Shi, H. H., Yan, Y., Zheng, G. M., \& Rittschof, D. 2018. Microplastics in oysters Saccostrea cucullata along the Pearl River Estuary, China. Environmental Pollution, 236, 619625.

Liebezeit, G., \& Dubaish, F. 2012. Microplastics in Beaches of the East Frisian Islands Spiekeroog and Kachelotplate. Bulletin of Environmental Contamination and Toxicology, 89(1), 213-217. 
Lippiat, S., Opfer, S., \& Arthur, C. 2013. Marine debris monitoring and assessment: recommendations for monitoring debris trends in the marine environment.

Lithner, D., Larsson, A., \& Dave, G. 2011. Environmental and health hazard ranking and assessment of plastic polymers based on chemical composition. Science of the Total Environment, 409(18), 3309-3324.

Lolodo, D., \& Nugraha, W., A. 2019. Mikroplastik Pada Bulu Babi Dari Rataan Terumbu Pulau Gili Labak Sumenep. Jurnal Kelautan: Indonesian Journal of Marine Science and Technology, 12(2), 112-122.

Lusher, A., Hollman, P., \& Mandoza-Hill, J. 2017. Microplastics in fisheries and aquaculture. In FAO Fisheries and Aquaculture Technical Paper, 615.

Lusher, A. L., McHugh, M., \& Thompson, R. . 2013. Occurrence of microplastics in the gastrointestinal tract of pelagic and demersal fish from the English Channel. Marine Pollution Bulletin, 67(1-2), 94-99.

Mani, T., Hauk, A., Walter, U., \& Burkhardt-Holm, P. 2015. Microplastics profile along the Rhine River. Scientific Reports, 5, 1-7.

Masanti, Y. D. 2017. Identifikasi Mikroplastik Pada Ikan Belanak (Mugil cephalus) Di Tambak Ngebruk, Semarang. Skripsi, Universitas Katolik Soegijapranata Semarang.

Muchlisin, Z.A., Musman, M., \& Siti Azizah, M.N. 2010. Lengthweight relationship and condition factors of two threatened fishes, Rasbora tawarensis and Poropuntius tawarensis, endemic to Lake Laut Tawar, Aceh Province, Indonesia. Journal of Applied Ichtiology, 26(6), 949-953.

Munandar, K., \& Eurika, N. 2016. Keanekaragaman Ikan yang Bernilai Ekonomi dan Kandungan Logam Berat Pb dan Cd pada Ikan Sapu-Sapu di Sungai Bedadung Jember. In Proceeding Biology Education Conference: Biology, Science, Enviromental, and Learning, 13(1), 717-722.

Murphy, F., Russell, M., Ewins, C., \& Quinn, B. 2017. The uptake of macroplastic \& microplastic by demersal \& pelagic fish in the Northeast Atlantic around Scotland. Marine Pollution Bulletin, 122(1-2), 353-359.

Neves, D., Sobral, P., Ferreira, J. L., \& Pereira, T. 2015. Ingestion of microplastics by commercial fish off the Portuguese coast. Marine Pollution Bulletin, 101(1), 119-126.

Nor, N. H. M., \& Obbard, J. P. 2014. Microplastics in Singapore's Coastal Mangrove Ecosystems. Marine Pollution Bulletin, 79(1-2), 78-283.

Peng, G.Y., Zhu, B.S., Yang, D.Q., Su, L., Shi, H.H., Li, D.D. 2017. Microplastics in sediments of the Changjiang Estuary, China. Environmental Pollution, 225, 283-290.

Permatasari, D. R., \& Radityaningrum, A. D. (2020). Kajian Keberadaan Mikroplastik Di Wilayah Perairan: Review. Seminar Nasional Sains Dan Teknologi Terapan VIII, 499-506.

Phillips, M. B., \& Bonner, T. H. 2015. Occurrence and amount of microplastic ingested by fishes in watersheds of the Gulf of Mexico. Marine Pollution Bulletin, 100(1), 264 269.

Piarulli, S., Scapinello, S., Comandini, P., Magnusson, K., Granberg, M., Wong, J. X. W., Sciutto, G., Prati, S., Mazzeo, R., Booth, A. M., \& Airoldi, L. 2019. Microplastic in wild populations of the omnivorous crab Carcinus aestuarii: A review and a regional-scale test of extraction methods, including microfibres. Environmental Pollution, 251, 117-127.

Prabowo, G. R. . 2019. Kandungan Mikroplastik Pada Ikan
Sapu-Sapu (Hypostomus Plecostomus) Di Kali Krukut. Skripsi, Universitas Bakrie.

Puspitasari, R. L., Elfidasari, D., Sasaerila, Y., Qoyyimah, F. D., \& Fatkhurokhim, F. 2018. Deteksi Bakteri Pencemar Lingkungan (Coliform) Pada Ikan Sapu-Sapu Asal Sungai Ciliwung. Jurnal Al-Azhar Indonesia Seri Sains dan Teknologi, 4(1), 24-27.

Rahmadhani, F. 2019. Identifikasi Dan Analisis Kandungan Mikroplastik Pada Ikan Pelagis Dan Demersal Serta Sedimen Dan Air Laut Di Perairan Pulau Mandangin Kabupaten Sampang. Skripsi, Universitas Islam Negeri Sunan Ampel Surabaya.

Ratnasari, I. 0. 2017. Identifikasi Jenis Dan Jumlah Mikroplastik Pada Ikan Nila Hitam (Oreochromis Niloticus) Di Perairan Air Payau Semarang. Skripsi, Universitas Katolik Soegijapranata Semarang.

Rochman, C. M., Tahir, A., Williams, S. L., Baxa, D. V., Lam, R. Miller, J. T., Teh, F. C., Werorilangi, S., \& Teh, S. J. 2015. Anthropogenic debris in seafood: Plastic debris and fibers from textiles in fish and bivalves sold for human consumption. Scientific Reports, 5, 1-10.

Sari, K. 2018. Keberadaan Mikroplastik pada Hewan Filter Feeder di Padang Lamun Kepulauan Spermonde Kota Makasar. Skripsi. Program Studi Ilmu Kelautan Fakultas Ilmu Kelautan dan Perikanan. Universitas Hasanuddin.

Scherer, C., Brennholt, N., Reifferscheid, G., \& Wagner, M. 2017. Feeding type and development drive the ingestion of microplastics by freshwater invertebrates. Scientific Reports, 7(1), 1-9. 7

Slootmaekers, B., Catarci Carteny, C., Belpaire, C., Saverwyns, S., Fremout, W., Blust, R., \& Bervoets, L. 2019. Microplastic contamination in gudgeons (Gobio gobio) from Flemish rivers (Belgium). Environmental Pollution, 244, 675-684.

Storck, F. R., Karlsruhe, T., Kools, S. A. E., Institute, K. W. R., \& Pfeiffer, S. R. 2015. Microplastics in Fresh Water Resources. Journal of Science Brief, 72(5), 1455-1457.

Sun, X., Li, Q., Shi, Y., Zhao, Y., Zheng, S., Liang, J., Liu, T., \& Tian, Z. 2019. Characteristics and retention of microplastics in the digestive tracts of fish from the Yellow Sea. Environmental Pollution, 249, 878-885.

Teuten, E. L., Saquing, J. M., Knappe, D. R. U., Barlaz, M. A., Jonsson, S., Björn, A., Rowland, S. J., Thompson, R. C., Galloway, T. S., Yamashita, R., Ochi, D., Watanuki, Y., Moore, C., Viet, P. H., Tana, T. S., Prudente, M., Boonyatumanond, R., Zakaria, M. P., Akkhavong, K., ... Takada, H. 2009. Transport and release of chemicals from plastics to the environment and to wildlife. Philosophical Transactions of the Royal Society B: Biological Sciences, 364(1526), 2027-2045.

Thevenon, F., Carroll, C. 2015. Plastic debris in the ocean: the characterization of marine plastics and their environmental impacts, situation analysis report. IUCN Librasy System. ISBN: 978-2-8317-1696-1.

Tosetto, L., Williamson, J. E., \& Brown, C. 2017. Trophic transfer of microplastics does not affect fish personality. Animal Behaviour, 123, 159-167.

Vandermeersch, G., Van Cauwenberghe, L., Janssen, C. R., Marques, A., Granby, K., Fait, G., Kotterman, M. J. J., Diogène, J., Bekaert, K., Robbens, J., \& Devriese, L. 2015. A critical view on microplastic quantification in aquatic organisms. Environmental Research, 143, 4655 .

Vendel, A. L., Bessa, F., Alves, V. E. N., Amorim, A. L. A., Patrício, J., \& Palma, A. R. T. 2017. Widespread 
microplastic ingestion by fish assemblages in tropical estuaries subjected to anthropogenic pressures. Marine Pollution Bulletin, 117(1-2), 448-455.

Virsek, M. K., Palatinus, A., Koren, S., Peterlin, M., Horvat, P., \& Krzan, A. 2016. Protocol for Microplastics Sampling on the Sea Surface and Sample Analysis. Journal of Visualized Experiments : JoVE, 118, 1-9.

Wagner, M., Scherer, C., Alvarez-Munoz, D., Brennholt, N., Bourrain, X., Buchinger, S., Fries, E., Grosbois, C., Klasmeier, J., Marti, T., Rodriguez-Mozaz, S., Urbatzka, R., Vethaak, A. D., Winter-Nielsen, M., \& Reifferscheid, G. 2014. Microplastics in freshwater ecosystems: what we know and what we need to know. Environmental Science Europe, 26(1), 1-9.

Wijaya, B. A., \& Trihadiningrum, Y. 2019. Pencemaran Mesodan Mikroplastik di Kali Surabaya pada Segmen Driyorejo hingga Karang Pilang. Jurnal Teknik ITS, 8(2), G211-G216.

Wilcox, C., Mallos, N. J., Leonard, G. H., Rodriguez, A., \& Hardesty, B. D. 2016. Using expert elicitation to estimate the impacts of plastic pollution on marine wildlife. Marine Policy, 65, 107-114.

Woodall, L. C., Sanchez-Vidal, A., Canals, M., Paterson, G. L. J., Coppock, R., Sleight, V., Calafat, A., Rogers, A. D., Narayanaswamy, B. E., \& Thompson, R. C. 2014. The deep sea is a major sink for microplastic debris. Royal Society Open Science, 1(4), 2-8.

Wright, S. L., \& Kelly, F. J. 2017. Plastic and Human Health: A
Micro Issue? Environmental Science and Technology, 51(12), 6634-6647.

Wright, S. L., Thompson, R. C., \& Galloway, T. S. 2013. The physical impacts of microplastics on marine organisms: a review. Environmental Pollution, 178, 483-492.

Yudhantari, C. I., Hendrawan, I. G., \& Puspitha, N. L. P. R. 2019. Kandungan Mikroplastik pada Saluran Pencernaan Ikan Lemuru Protolan (Sardinella Lemuru) Hasil Tangkapan di Selat Bali. Journal of Marine Research and Technology, 2(2), 47-51.

Yumni, Z., Yunita, D., \& Sulaiman, M. I. 2020. Identifikasi Cemaran Mikroplastik pada Ikan Tongkol ( Euthynnus affinis C .) dan Dencis ( Sardinella lemuru ) di TPI Lampulo , Banda Aceh. Jurnal Ilmiah Mahasiswa Pertanian, 5(1), 316-320.

Zhang, W., Zhang, S., Wang, J., Wang, Y., Mu, J., Wang, P., Lin, X., \& Ma, D. 2017. Microplastic pollution in the surface waters of the Bohai Sea, China. Environmental Pollution, 231, 541-548.

Zubris, K. A. V., \& Richards, B. K. 2005. Synthetic fibers as an indicator of land application of sludge. Environmental Pollution, 138(2), 201-211. 